DOI: https://doi.org/10.15688/lc.jvolsu.2017.1.1

UDC 34.342 .7

LBC 67.404

\title{
THE PROBLEMS OF LEGAL EDUCATION AND AWARESSNESS OF CHILDREN IN THE RUSSIAN FEDERATION
}

\author{
Olga A. Ruzakova
}

Russian Academy of National Economy and Public Administration under the President of the Russian Federation, Moscow, Russian Federation

\section{Aleksey B. Ruzakov}

Moscow Financial and Industrial University “Synergy”, Moscow, Russian Federation

Introduction: any state is interested in the younger generation's awareness and respect for the nationwide laws. It is extremely important for young people not only to know and respect the laws, but also to understand their essence, and seek to abide them. Only then we can talk about the high level of legal conciseness and legal culture of the younger generation. It is the constant policy of the legal education and awareness of children and youth and, as a result, the forming of the high legal culture of the youth that can fully implement such basic values and principles of the society as the rule of law, the priority of the inalienable rights and freedoms of an individual, the ensuring of their protection. The aim of the study is to analyze the problems connected with the legal education and awareness of children and youth in the Russian Federation and offer the optimal solutions. The methods used are the following: to achieve the objectives of the study there have been used the comparative and legal, formal and legal, systemic and logical methods. The results: there have been analyzed the key measures of a public nature which are taken by the government to solve the problems of the legal education and awareness of youth. There has been set the necessity of dividing the state measures into the measures in the field of education and the upbringing of the younger generation, the legal education and judicial training. The necessity of dividing these measures depending on the age of the children and young people has been pointed out. The conclusions: there has been proved the necessity of the classification of the government measures aimed at the legal education and awareness depending on the content of education and the age of the younger generation. There have been established the elements of the legal education and awareness, including the importance played by the family and educational institutions. One of the important elements of the legal education of children is the prevention of juvenile delinquency. It has been proved that the solution of these problems should be of integrated character at the level of both the legislative, executive, and the judicial bodies taking into account the positive international experience, including with the aim of unifying the international law.

\section{ПРОБЛЕМЫ ПРАВОВОГО ВОСПИТАНИЯ И ПРОСВЕЩЕНИЯ ДЕТЕЙ В РОССИЙСКОЙ ФЕДЕРАЦИИ \\ Ольга Александровна Рузакова}

Российская академия народного хозяйства и государственной службы при Президенте РФ, г. Москва, Российская Федерация 


\section{Алексей Борисович Рузаков}

Московский финансово-промышленный университет «Синергия», г. Москва, Российская Федерация

Введение: любое государство заинтересовано в том, чтобы подрастающее поколение знало и уважало действующие на его территории законы. При этом крайне важно, чтобы молодежь не только знала и уважала законы, но и понимала их сущность, стремилась их соблюдать. Только тогда мы сможем говорить о высоком уровне правосознания и правовой культуры подрастающего поколения. Лишь при постоянном проведении политики правового воспитания и просвещения детей и молодежи и формировании в результате этого высокой правовой культуры молодежи могут быть в полной мере реализованы такие базовые ценности и принципы жизни общества, как верховенство закона, приоритет неотчуждаемых прав и свобод человека, обеспечение их защиты. Цель исследования: проанализировать проблемы, связанные с правовым воспитанием и просвещением детей и молодежи в Российской Федерации, и предложить оптимальные пути их решения. Методы: при проведении исследования для достижения поставленной цели в данной работе были использованы сравнительно-правовой, формально-юридический, системный и логический методы. Результаты: проанализированы основные меры государственного характера, которые предприняты государством для решения проблем правового воспитания и просвещения молодежи. Установлена необходимость разделения государственных мер на меры в области образования и воспитания подрастающего поколения, юридического образования и подготовки юридических кадров. Указано на необходимость деления указанных мер в зависимости от возраста детей и молодежи. Выводы: обоснована необходимость классификации государственных мер, направленных на правовое воспитание и просвещение, в зависимости от содержания образования и возраста подрастающего поколения. Установлены элементы правового воспитания и просвещения, в числе которых важное значение имеют семья и образовательные учреждения. Одним из немаловажных элементов правового воспитания детей является также профилактика правонарушений среди несовершеннолетних. Доказано, что решение поставленных проблем должно носить комплексный характер на уровне как законодательных, так и исполнительных, судебных органов с учетом положительного зарубежного опыта, в том числе и с целью унификации норм международного права.

Ключевые слова: правовое воспитание, правовое просвещение, государственные меры, защита прав ребенка, семья, правовое образование.

\section{Введение}

Развитие правового государства, формирование гражданского общества в России требуют высокой правовой культуры. «Сегодня в условиях бурного изменения законодательства Российской Федерации и процессов модернизации образования возрастает значимость исследования как теоретических, так и практических аспектов формирования правовой культуры» [3, с. 177]. Без сформированной правовой культуры не могут быть в полной мере реализованы такие базовые ценности, как верховенство закона, приоритет неотчуждаемых прав и свобод человека, обеспечение их защиты.

В связи с этим вопросы правового просвещения приобретают особую актуальность, в том числе в среде подрастающего поколения.

Все общественное имеет в своей основе политику и предопределяется политической реальностью. Политическое формирует мировоззренческие, культурные, духовные, психологические, социальные установки, на которых основывается любой человеческий коллектив [2, с. 99]. Именно в силу этого правовое образование и воспитание является одним из важнейших направлений развития государственной политики в Российской Федерации, что отражено в утвержденных Президентом РФ 28 апреля 2011 г. «Основах государственной политики Российской Федерации в сфере развития правовой грамотности и правосознания граждан» (№ Пр-1168) [6].

\section{Государственные меры, направленные на правовое воспитание и просвещение детей и молодежи}

В числе мер, направленных на обеспечение названного направления в области образования и воспитания подрастающего поколения, юридического образования и подготовки юридических кадров, можно назвать:

1) включение в примерную основную общеобразовательную программу дошкольного образования, примерную основную образовательную программу начального обще- 
го образования задач приобщения детей к элементарным общепринятым нормам и правилам взаимоотношений со сверстниками и взрослыми;

2) развитие практики обучения основам права в образовательных учреждениях различного типа и вида, поддержку у различных вариантов региональных моделей правового образования, разработку учебных курсов, включающих правовую тематику, соответствующих образовательных программ, учебных и методических пособий;

3) применение специальных программ правового образования и воспитания детей, находящихся в трудной жизненной ситуации, трудных подростков и несовершеннолетних правонарушителей и др.

Наряду с общими декларативными нормами важное значение имеют комплексные действия семьи, учебных и других воспитательных организаций, средств массовой информации в обеспечении правового воспитания несовершеннолетних.

Правовое воспитание - это процесс целеустремленного и систематического воздействия на сознание и культуру поведения членов общества, осуществляемый для достижения необходимого уровня правовых знаний, выработки глубокого уважения к закону и привычки точного соблюдения его требований на основе личного убеждения [4, с. 340]. И данный процесс требует своей реализации начиная с дошкольного возраста. Лучшим примером в этом выступают родители и другие члены семьи ребенка, учителя, воспитатели.

Воспитание осуществляется в процессе организованной совместной деятельности семьи и образовательных учреждений, детских и молодежных организаций, общественности [1, c. 380].

Характер воспитания и моральный климат в семье, а также качественный уровень воспитания и обучения в образовательных учреждениях оказывают непосредственное влияние на формирование правовой культуры и позитивного типа правосознания и поведения ребенка.

Безусловно, правовое воспитание - это сложное для реализации право, являющееся элементом права и обязанности воспитания детей, принадлежащих в первую очередь ро- дителям в соответствии с ч. 2 ст. 38 Конституции РФ, ст. 54 Семейного кодекса РФ.

По мнению А.М. Нечаевой, понятие «воспитание», будучи не правовым, а сугубо педагогическим, тем не менее относится к основополагающим, составляющим фундамент многих правил, определяющих семейноправовой статус ребенка [5, с. 30].

Со стороны учебных организаций правовое воспитание может проводиться как в направлении предоставления знаний по правовым вопросам, так и объяснения необходимости законопослушного поведения, формирования уважения к закону, привития идеи добросовестного исполнения обязанностей и соблюдения правовых норм.

Уже в начальной школе дети проявляют интерес к правовым явлениям и могут успешно усваивать отдельные положения истории права, семейного, трудового, уголовного и гражданского права. В возрасте 9-11 лет детей интересуют вопросы вступления в брак, отношений между членами семьи, права ребенка в разных сферах, вопросы совершения ребенком сделок, возможности распоряжаться денежными средствами и своим имуществом, а также нарушения, которые допускают люди в своем поведении, и последствия таких нарушений. Наряду с уже преподаваемыми в начальной школе дисциплинами, такими как основы религии, основы этикета, в четвертом классе школьники могли бы изучать основы правовых знаний. Опыт повсеместного школьного изучения норм различных религий свидетельствует о возможности изучения и норм права, в основе которых также лежат отношения между людьми, мораль, нравственность, справедливость. Обсуждение с детьми такого рода вопросов как никогда актуально для современного общества.

Переход на уровень систематизации правовых знаний в части отдельных отраслей в рамках курсов «Основы государства и права», «Правоведение», «Обществознание» после получения базовых знаний в начальной школе возможен уже в 13-14 лет. В 14 лет дети должны обладать информацией об основах конституционного строя, правопорядка в Российской Федерации, о тех правах и ответственности, которые предусмотрены гражданским правом для частично дееспособных лиц, 
об ответственности, наступающей в уголовном праве с четырнадцатилетнего возраста, а также об административной и уголовной ответственности подростков в возрасте от 16 лет. Безусловно, самым важным аспектом в правовом обучении является близость рассматриваемых вопросов во взаимосвязи с жизненными ситуациями, демонстрация ребенку того, что полученные знания ему пригодятся в жизни и, обладая ими, он многое приобретает по сравнению с теми людьми, которые лишены этих знаний или умения ими воспользоваться.

Другим немаловажным элементом правового воспитания детей является профилактика правонарушений среди несовершеннолетних. Не секрет, что преступность и административные правонарушения среди детей и подростков в нашем государстве приобрели угрожающие масштабы и стали одной из главных социальных проблем [7].

В числе наиболее распространенных причин детской преступности - постоянно снижающийся уровень социально-экономического развития страны, декларативный, далеко не всегда реализуемый на практике характер конституционных норм, провозглашающих основы правового государства, верховенства закона и т. д., отсутствие системы правового образования и воспитания на всех этапах обучения детей в образовательных учреждениях (большее внимание уделяется религиозным знаниям, нежели правовым, откровенное насаждение большинством средств массовой информации культа насилия, вседозволенности, пренебрежения к обычаям, традициям и истории своего Отечества.

\section{Выводы}

Решение поставленных проблем должно носить комплексный характер на уровне как законодательных, так и исполнительных, судебных органов с учетом положительного зарубежного опыта, в том числе и с целью унификации норм международного права. Так, в части защиты детей от негативного воздействия средств массовой информации примером унификации на уровне Евросоюза может служить Директива № 2010/13/ЕС Европейского парламента и Совета Европейского со- юза «О координации некоторых законодательных, регламентарных и административных положений, действующих в государствах-членах ЕС, относительно оказания аудиовизуальных медиа-услуг» (принята в г. Страсбурге 10 марта 2010 г.), в которой признается обеспокоенность законодателей наличием вредоносного содержания в аудиовизуальных медиа-услугах и необходимость введения защиты физического, умственного и нравственного развития несовершеннолетних. Аудиовизуальные коммерческие сообщения не должны причинять физического или морального ущерба несовершеннолетним, склонять несовершеннолетних к покупке товаров или оказанию услуг, используя их неопытность и доверчивость, побуждать их убеждать родителей или других лиц в совершении покупки рекламируемых товаров или услуг, использовать особое доверие несовершеннолетних у родителей, учителей или других лиц или неоправданно показывать несовершеннолетних в опасных ситуациях. В Российской Федерации меры по защите детей от негативного воздействия средств массовой информации нашли отражение в Федеральном законе от 29 декабря 2010 г. № 436-Ф3 «О защите детей от информации, причиняющей вред их здоровью и развитию» [8].

Воспитание юридическими вузами высококвалифицированных кадров профессиональных юристов, способных донести до детей правовые знания, совместно с педагогическими учебными учреждениями является также одним из важнейших и эффективных направлений решения поставленных задач правового воспитания и просвещения несовершеннолетних.

\section{СПИСОК ЛИТЕРАТУРЫ}

1. Большая советская энциклопедия. В 30 т. Т. 5 / гл. ред. А. М. Прохоров. - 3-е изд. - М. : Сов. энцикл., 1971. $-436 \mathrm{c}$.

2. Грачев, Н. И. Политика и экономика в онтологии современного государства / Н. И. Грачев // Вестник Волгоградского государственного университета. Серия 5, Юриспруденция. - 2016. № 2 (31). - C. 93-100.

3. Епифанов, А. Е. Рец. на кн.: Павленко, Е. М. Образование в области прав человека как основа формирования правовой культуры и культуры прав 
человека в Российской Федерации [Текст] : монография / Е. М. Павленко. - М. : Права человека, 2016. - 216 с. / А. Е. Епифанов // Вестник Волгоградского государственного университета. Серия 5, Юриспруденция. - 2016. - № 2 (31). - С. 177-179.

4. Мелехин, А. В. Теория государства и права / А. В. Мелехин. - М. : Маркет ДС, 2007. - 640 с.

5. Нечаева, А. М. Семейное право: актуальные проблемы теории и практики / А. М. Нечаева. - М. : Юрайт-Издат, 2007. - 450 с.

6. Основы государственной политики Российской Федерации в сфере развития правовой грамотности и правосознания граждан : (утв. Президентом РФ 28 апр. 2011 г. № Пр-1168) // Российская газета. - 2011. - 4 июля (№ 151).

7. Состояние преступности в Российской Федерации : (информация МВД России). - Электрон. текстовые дан. - Режим доступа: http://sun-mirror. duma.gov.ru/ntc/ifgdn/bpa/ifgd_tree.php?parit= 27142. - Загл. с экрана.

8. Федеральный закон «О защите детей от информации, причиняющей вред их здоровью и развитию» от 29 дек. 2010 г. № 436-Ф3 : (ред. от 29 июня 2015 г.) // Собрание законодательства РФ. - 2011. № 1. - Ст. 48.

9. Численность населения Российской Федерации по полу и возрасту // Федеральная служба государственной статистики. - Электрон. текстовые дан. - Режим доступа: http://anunt3.duma.gov.ru/ BGD/B13_111/IssWWW. - Загл. с экрана.

\section{REFERENCES}

1. Prokhorov A.M., ed. Bolshaya sovetskaya entsiklopediya. V 30 t. T. 5 [The Great Soviet Encyclopedia. In 30 vols. Vol. 5]. 3rd ed. Moscow, Sovetskaya entsiklopediya Publ., 1971. 436 p.

2. Grachev N.I. Politika i ekonomika v ontologii sovremennogo gosudarstva [Politics and Economics in the Ontology of the Modern State]. Vestnik Volgogradskogo gosudarstvennogo universiteta. Seriya 5, Yurisprudentsiya [Science Journal of Volgograd State University. Jurisprudence], 2016, no. 2 (31), pp. 93-100.

3. Epifanov A.E. Rets. na kn.: Pavlenko, E. M. Obrazovanie v oblasti prav cheloveka kak osnova formirovaniya pravovoy kultury i kultury prav cheloveka v Rossiyskoy Federatsii [Tekst] : monografiya / E. M. Pavlenko. - M. : Prava cheloveka, 2016. - 216 p. [Book Review: Pavlenko E.M. Education in the Field of Human Rights as the Basis of Formation of Legal Culture and Human Rights Culture in the Russian Federation [Text]: Monograph. Moscow, Prava cheloveka Publ., 2016. 216 p.]. Vestnik Volgogradskogo gosudarstvennogo universiteta. Seriya 5, Yurisprudentsiya [Science Journal of Volgograd State University. Jurisprudence], 2016, no. 2 (31), pp. 177-179.

4. Melekhin A.V. Teoriya gosudarstva i prava [The Theory of State and Law]. Moscow, Market DS Publ., 2007.640 p.

5. Nechaeva A.M. Semeynoe pravo: aktualnye problemy teorii i praktiki [The Family Law: Urgent Problems of Theory and Practice]. Moscow, YuraytIzdat Publ., 2007. 450 p.

6. Osnovy gosudarstvennoy politiki Rossiyskoy Federatsii v sfere razvitiya pravovoy gramotnosti i pravosoznaniya grazhdan: utverzhden Prezidentom RF 28.04.2011 № Pr-1168 [The Foundations of State Policy of the Russian Federation in the Sphere of Development of Legal Literacy and Legal Awareness of Citizens]. Rossiyskaya gazeta, 2011, July 14 (no. 151).

7. Sostoyanie prestupnosti v Rossiyskoy Federatsii: (informatsiya MVD Rossii) [Criminality Condition in the Russian Federation: (Information of the Ministry of Internal Affairs of Russia)]. Available at: http://sun-mirror.duma.gov.ru/ntc/ifgdn/bpa/ ifgd_tree. php?parit=27142.

8. Federalnyy zakon "O zashchite detey ot informatsii, prichinyayushchey vred ikh zdorovyu i razvitiyu” ot 29.12.2010 № 436-FZ: (red. ot 29.06.2015) [The Federal Law "On the Protection of Children from Information Harmful to Their Health and Development" of December 29, 2010 no. 436-FL: (ed. of June 29, 2015)]. Sobranie zakonodatelstva $R F$, 2011, no. 1 , art. 48 .

9. Chislennost naseleniya Rossiyskoy Federatsii po polu i vozrastu [The Population of the Russian Federation by Sex and Age]. Federalnaya sluzhba gosudarstvennoy statistiki [Federal State Statistics Service]. Available at: http://anunt3.duma.gov.ru/BGD/ B13_111/IssWW.

\section{Information About the Authors}

Olga A. Ruzakova, Doctor of Juridical Sciences, Professor, Russian Academy of National Economy and Public Administration under the President of the Russian Federation, Deputy Head of the Office of the State Duma Committee on State Building and Law, Okhotnyy Ryad St., 1, 103265 Moscow, Russian Federation,ruza@duma.gov.ru. 
О.А. Рузакова, А.Б. Рузаков. Проблемы правового воспитания и просвещения детей в РФ

Aleksey B. Ruzakov, Senior Teacher, Department of Civil Law and Procedure, Moscow Financial and Industrial University "Synergy", Meshchanskaya St., 9/14, build. 1, 129090 Moscow, Russian Federation, ruza@duma.gov.ru.

\section{Информация об авторах}

Ольга Александровна Рузакова, доктор юридических наук, профессор, Российская академия народного хозяйства и государственной службы при Президенте РФ, заместитель руководителя аппарата Комитета Государственной Думы по государственному строительству и законодательству, ул. Охотный Ряд, 1, 103265 г. Москва, Российская Федерация, ruza@duma.gov.ru.

Алексей Борисович Рузаков, старший преподаватель кафедры гражданского права и процесса, Московский финансово-промышленный университет «Синергия», ул. Мещанская, 9/14, стр. 1, 129090 г. Москва, Российская Федерация, ruza@duma.gov.ru. 